University of Wollongong

Research Online

Faculty of Arts - Papers (Archive)

Faculty of Arts, Social Sciences \& Humanities

$1-1-2005$

\title{
Challenges in understanding public responses and providing effective public consultation on water reuse
}

\author{
Stewart Russell \\ University of Wollongong, stewart_russell@uow.edu.au \\ Gregory R. Hampton \\ University of Wollongong, gregh@uow.edu.au
}

Follow this and additional works at: https://ro.uow.edu.au/artspapers

Part of the Arts and Humanities Commons, and the Social and Behavioral Sciences Commons

\section{Recommended Citation}

Russell, Stewart and Hampton, Gregory R., Challenges in understanding public responses and providing effective public consultation on water reuse 2005, 587-600.

https://ro.uow.edu.au/artspapers/610

Research Online is the open access institutional repository for the University of Wollongong. For further information contact the UOW Library: research-pubs@uow.edu.au 


\title{
Challenges in Understanding Public Responses and Providing Effective Public Consultation on Water Reuse
}

\author{
S. Russell ${ }^{a^{*}}$, G. Hampton ${ }^{b}$ \\ ${ }^{a}$ School of Social Sciences, Media \& Communication, University of Wollongong, NSW 2522, Australia. \\ Tel: +61 242213088 , Fax +6124221 5341, E-mail: stewartouow.edn.au \\ ${ }^{b}$ Academic Services Division, University of Wollongong, NSW 2522, Australia. Tel: +61242213446 , \\ E-mail: greghoulow, eduan \\ *Corresponding author.
}

\begin{abstract}
This paper suggests key challenges facing our understanding of public responses to water recycling and our efforts to provide effective public consultation. The current understanding of public reactions to water recycling is insufficient to predict support in general or for specific schemes, and cannot obviate a thorough investigation and engagement for each proposal. Such support as is evident may not be robust. We need to provide better opportunities and mechanisms, and a wider scope, for community involvement. These entail a broader conception of the information needs of participants, and careful integration of education and consultation processes. Our discussion forms the rationale for a program of research as part of the OzAQUAREC project. We propose trialling discourse analysis methods, first, to examine the views expressed in focus groups and try to understand their social bases, and second, to facilitate interactions between technical practitioners, authorities and community groups.
\end{abstract}

Keywords: consultation, public responses, education, participation

\section{Introduction}

It is widely acknowledged that issues of public acceptance are among the most important for the future of water recycling in Australia and elsewhere. In a survey conducted through the Australian Water Association on research priorities, for example, 'factors affecting public acceptance of reuse' came top of the practitioners' list [1]. In the US, the WateReuse Foundation put out a call in 2003 for proposals on a major research project on these issues [2].

This paper does not report research results, as we are just embarking on a program of empirical work in the area. Nor does it attempt in this limited space a comprehensive review of the literature on public acceptance of water reuse, or to provide more than indicative references. Its primary purpose is to reflect on the key challenges first, facing our understanding of public responses to water recycling, and second, in providing effective and worthwhile public involvement. As a contribution to meeting these needs, we outline and justify our own research agenda: specific investigation and consultation approaches we want to pilot as part of the multidisciplinary Oz-AQUAREC project.

We are interested, like others in the field, not just in recording people's views, but in examining how they express them and understanding what influences them. For us, this is not only a behavioural or cognitive question but also a sociological and cultural one. First, we plan to apply discourse analytic approaches to understanding responses expressed in focus groups. These are aimed at eliciting and mapping the values, experiences, heuristics and judgements underlying responses on specific questions and options. Second we are interested in developing consultation approaches which deliberately pit contrasting discourses against each other. This should allow us to 
examine how public discourses on the issues mesh with - or clash with - the framing of the issues in policy, planning and technical circles. This side of the work also has a practical aim: facilitating dialogue may provide resolutions in contentious proposals.

Our central claims that follow may be disappointingly non-committal, qualified and complex for advocates of water reuse and for developers and managers of schemes. We argue however that it is vital for the future of reuse to face them squarely and devote adequate time and resources both to investigating the issues and the wider experience of public involvement, and to developing appropriate consultation approaches.

First, not nearly enough is known in general terms to predict likely community responses to water recycling in general and to specific proposals, and certainly not enough to obviate a thorough study and engagement specific to each scheme.

Second, we cannot yet be confident that community acceptance of recycled water will be robust in the face of changed circumstances and emerging concerns, including those beyond water provision.

Third, we need to recognise that all consultation exercises are simultaneously learning exercises, from the first mention of the idea of recycling. We need a broader conception of the understandings that people will need and demand; it goes beyond simply providing 'information'. This point means more careful thinking about appropriate forms of education and information, and appropriate opportunities for developing that understanding.

Fourth, we need to devise and provide better forms of community involvement. While the key principles - in particular, the need for a transparent process, open discussion of possible problems, and extensive provision of credible information - are now widely acknowledged in the abstract, it has to be said that community engagement in the water sector has not always lived up to them. Indeed, we still find a tendency to treat engagement with the community as a matter of persuasion, amenable to public relations techniques. If public acceptance is crucial to the future of water reuse, then we need to recognise the pivotal role that consultation must play.

\section{Understanding community responses}

\subsection{Existing work and experience}

Thirty years of research work on public responses to water recycling, and the limited number of reports of consultation exercises that are publicly available, provide some interesting and useful insights. As recycling is put on the agenda throughout the world, there is more useful work underway. One problem is that while there are many individual studies, there are relatively few attempts to review and digest their findings comprehensively and critically. Useful exceptions are a paper by Baumann [3], Hartley's report for the Water Environment Research Foundation [4], and a review by a CSIRO team [5].

The key problems for someone reviewing the work on responses to recycling are

- that individual studies do not provide substantive results which can be transferred readily across different contexts - indeed the authors usually caution against such generalisations;

- that the studies can to different degrees be criticised in relation to the usefulness of the results, the claims which are made for them, or the impressions which might be inferred from them; and

- that the approaches and methods in the studies are diverse, and theoretical frameworks and assumptions are often not made explicit. 
It is not surprising then that even those reviewers that have approached the studies critically and tried to go beyond simply relaying the findings in their own terms have found it difficult to reconcile the often inconsistent and contradictory claims.

\subsection{Uses and limitations of survey research}

Much work on water recycling has been based on surveys, aimed both at eliciting quantitative statements about the extent of support and at identifying factors which determine it. While there are many useful insights from this body of work, we remain sceptical for a number or reasons about the overall value of the endeavour, about the validity of some of the claims even for the population sampled, and about their transferability to other populations.

First, many surveys rest on the idea of a measurable and stable 'attitude', particularly in relation to health hazards. Theoretical work on risk perception and public participation indicates that responses develop in the course of interaction, discussion and education on technologies, their health implications and contextual issues. In particular, attempting to poll the views of people who have thought little about the issues before being confronted with a questionnaire on them, is of limited value.

Second, responses are strongly affected not just by conscious attempts to inform groups about recycling, but by related or parallel issues which come to public attention. As we argue later, responses could change dramatically if there were a widely publicised accident or health concern even in another sector. It is for this reason that consultation and information programmes must aim at producing a robust evaluation of the benefits and risks of water recycling.

Third, it would be dangerous to assume survey results even in outline could be transferred between contexts. We suspect that local factors, such as experience with water recycling and management issues, perceptions and record of the responsible organisations, and media coverage, have an enormous influence on people's views.

Fourth, responses are notoriously contingent on the circumstances, design and conduct of the survey. Answers can depend on a number of variables - choices of the researchers or circumstantial factors. In particular, any methods short of intensive interviews with open-ended questions tend to restrict responses to areas of concern and to a discursive framework that have been defined in advance by the researchers or their clients. They may in effect force participants to choose statements on attitudes they have not previously subscribed to or even considered.

In order to explain variations in the level of apparent support, researchers have often chased largely elusive correlations with socio-economic and demographic characteristics - income, education, gender, age, etc. - seemingly in the hope of capturing a formula that governs the degree of public approval and would allow them to predict the acceptance of a scheme by a particular population. That attempt is probably missing the point that responses may be far more context-dependent, far more influenced by contingent political and cultural factors and local experience, and, perhaps paradoxically, based on deep but usually unarticulated values.

Besides demographic variables, the other correlation that has become widely accepted and cited is the inverse dependence between acceptance and the likelihood of human contact with recycled water in specific applications, following the pioneering work of Bruvold. Certainly it makes sense intuitively. Bruvold's later work, however, shows that even this relation is not so straightforward. When people face a specific proposal rather than the idea of recycling in the abstract, the degree of contact may be less significant than their views on its wider environmental, health and economic implications $[6,7,8]$. 
We do not deny the usefulness of surveys and quantitative analyses as part of a broader research and consultation strategy. However, they must be carefully designed for specific and limited purposes and they should, as we argue later, be informed by a thorough qualitative exploration of user and public responses and the social factors underlying them.

\subsection{General findings on public responses}

Our comments on the limitations of quantitative work notwithstanding, we can point to some reasonable general claims emerging from existing work.

It is widely acknowledged that public support in principle for the idea of nonpotable use of recycled water is strong. It has been suggested the assumption of such support may have led authorities and developers in some places to neglect public consultation. If this is the case, this stance is thoroughly misguided: it cannot be assumed that if someone expresses support for recycling hypothetically they will necessarily approve of a specific scheme or be willing to use recycled water in practice.

Hartley's report for WERF [4] draws on a wide range of research results to indicate that support is likely to be greatest when:

- contact is minimal

- protection of human health is clear;

- protection of environment is a benefit;

- promotion of water conservation is a benefit;

- cost is reasonable;

- perception of wastewater as source of recycled water is minimal;

- community has high awareness of water supply problems;

- role of reclaimed water in overall water supply is clear,

- perception of quality of reclaimed water is high;

- confidence in local management of utilities and technologies is high.

It is evident that support for water recycling does correlate well with a general concern for the environment and natural resources, though this connection needs further exploration. It follows that education and information materials should emphasise, as publicity material for recycling schemes often does, the contribution that recycling can make to these aims, as well its direct and immediate benefits to the individual user.

However, we are all aware of evidence of adverse reactions to schemes and proposals in Australia and overseas. Much of the evidence is anecdotal, and the lurid headlines, websites and other interventions may be attributable to individuals rather than necessarily representing widespread reactions. That does not, however, rule out the possibility of concerted opposition and objections shared by a substantial fraction of a population. It is likely that opinion will be swayed strongly by active and vocal individuals or groups or by strong stances taken in the media.

Discussion of opposition to recycling initiatives has tended recently to focus on 'disgust' - the so-called 'yuck' factor: an emotional response to the idea of reusing water derived from sewage effluent [5]. Influential headlines and catchcries ('toilet to tap') have certainly reinforced the idea. These may be an effective way of swinging opinion against a proposal, and the underlying association may be a major stumbling block. However, we would caution against assuming that 'disgust' exhaustively explains negative public responses to the extent they are encountered. Nor should we take this simply as further evidence for the supposed inability of the public to make rational judgements, and assume that the efforts of educators have to be focussed solely on countering this. 


\subsection{Stability of public responses}

Not only can responses vary widely, but it would be unwise to assume that the generally supportive views expressed in many consultation exercises, and the absence of complaints reported in many existing recycling schemes, indicate an informed and robust acceptance by current users of the safety and quality of recycled water. Absence of evidence for concern is not the same as evidence for absence of concern.

First, people may have unarticulated concerns or grievances, even though they have not yet felt motivated to complain. Or they may have had no suitable outlet for that complaint. Second, even if there genuinely are no concerns at the moment, this could easily be disturbed by all sorts of events or influences:

- an incident producing contamination of the recycled water supply;

- a rise in public debate on water recycling in general;

- health incidents, scares, rumoürs or adverse media reports concerning schemes elsewhere;

- a revelation of previously unknown contaminants in recycled water,

- a rise in concern about known contaminants such as heavy metals, endocrine disrupters and other trace organics, or publicity about a reassessment of their health risks; or

- potential new users demanding more information or greater reassurance than had been required before.

Many commentators acknowledge that, as Dillon observes, "... a failure at even one site may do much to damage implementation of water reuse nationally' [1]. Concern over the quality and health implications of recycled water could thus be volatile. Moreover, the reaction of users to any of the influences above would most likely be exacerbated by a perception that past consultation had not been adequate.

It is also likely that opinion will be swayed strongly by other events and concerns, some unrelated or only tenuously linked to water recycling. These associations may have a positive effect, like the recent drought across New South Wales. Conversely, one can point to the experience in Europe of a series of food safety scandals: listeria in British eggs, dioxin in Belgian chicken and chocolates, BSE, foot and mouth disease. In these cases, mistakes and cover-ups, apart from damaging specific industries and markets, created a broad and deep distrust of policy makers and regulatory authorities.

From the point of view of a developer or a water recycling advocate, then, the key aim of consultation and education exercises has to be to build more solid support, based on a well developed and mature understanding among users and wider audiences. We can build on the in-principle goodwill towards recycling that is evident already, but we have to give it deeper roots.

\subsection{Reactions to public responses}

At the same time as widespread support is acknowledged, there is considerable frustration among some advocates of water recycling that vocal sections of the public may be holding back its wider introduction. It is assumed that safety issues have been resolved and that unfavourable public responses are based on misperceptions of the health risks and perhaps biased media reporting. Discussions often contrast the 'emotional' response of the public and their 'perception' of the risks with the 'rational' assessment of experts and the 'real' risks. Starting out with this attitude, and the dubious assumptions it entails, does not help create a productive dialogue.

There is still a widespread tendency to assume that if people are not responding in the way experts think they should to information on health hazards, the mismatch is 
caused by ignorance, erroneous beliefs, faulty reasoning, emotions overruling rationality, or a failure to get risks into perspective. The answer is taken to be more and better information. That reaction tends to assume that the technical choices that have been made - selection among different options, the ways risks have been assessed, the criteria used in deciding something is 'safe' - were themselves value-free. It is reflected in the categories, still unfortunately in common use, of 'real' versus 'perceived' risks.

Underlying those public reactions may be judgements that are not about the level of risk or the other issues that engineers or risk assessors assume, but about the institutions in charge of a scheme, about the trustworthiness of government and regulatory agencies, about past broken promises of the last good thing someone was trying to sell. If our information and educational efforts focus solely on questions of physical risk, they fail to acknowledge the much broader basis on which people judge the acceptability of new technological systems $[5,9,10,11,12]$, To treat these issues as irrelevant in assessing the merits of a technological system is just as much a value judgement as whatever it is that motivates lay people's responses.

Ignorance and misunderstanding may well exist, and people's views on recycling will undoubtedly shift as they get more information and as their understanding develops. However, they may not change in the way that the providers of that information assume or want We cannot assume that people's judgements, or the way they make them, will or should eventually correspond to those of the technical experts.

\section{Approaches to public involvement}

We limit ourselves here to a few aspects of public involvement that follow from our discussion above and that have provided the motivation for our research: on the justifications for involvement; on its scope and terms; and on the role and character of the information provided.

\subsection{Justifications for public involvement}

Public consultation is increasingly being mandated for public and private infrastructure and utility developments, even if only in the vaguest of terms. It is increasingly a public expectation. And we could of course make arguments for extensive community involvement in terms of democratic principles.

The key points have been spelled out repeatedly in the water sector as elsewhere:

- that processes should be transparent;

- that people should be given comprehensive and credible information;

- that deliberation should encompass general water management in a region and start before specific recycling schemes are planned;

- that there should be open discussion of possible problems;

- that people should be informed at the outset of the extent to which their preferences will be taken into account.

The contrast between different levels of involvement, from token information provision through to community control, is frequently acknowledged in general discussions here and in other sectors in a nod to Arnstein's ladder [13]. Our impression is that it is then promptly ignored and the practice here as elsewhere has seldom got far along that spectrum. Ideally a community should be allowed to provide input to decision-making and genuine influence over the possible outcomes, rather than simply being expected to consider and endorse completed plans [14].

To the principled arguments for genuine public involvement we can add a number of potential benefits to the developer, water authority or regulator [15]. It may: 
- help generate consensus on the benefits and value of the project, a sense of involvement and control, and a commitment to its successful implementation and operation;

- help avoid objections at the time of implementation, or lack of support and cooperation if there are operational difficulties and unforeseen problems to be overcome later; or reduce the time and effort spent dealing with individual objections and misunderstandings;

- educate users on required practices and precautions, help generate commitment to good user practices, speed up the changeover to new practices, and help avoid problems with inappropriate actions; allow greater user discretion and involvement in day-to-day operation and hence reduced levels of automation in end use installations;

- increase recognition of the value of water generally, and broader environmental and civic awareness;

- encourage users to spread the message of the benefits of water recycling;

- increase willingness to pay water charges;

- reassure users and the wider public that the developer is open, honest, accountable and trustworthy, and help interactions on other issues;

- provide an important contribution : to knowledge of local operating conditions, the practices of users, and the way they interact with the system, including their detailed patterns of water use and appliance operation, which can feed directly into better design of the system and influence its success; compensate for the tendency of designers to make unrealistic assumptions about how users interact with the system and how reliable their behaviour will be;

- alert developers and regulators to issues not currently addressed in guidelines or safety and quality criteria.

On top of all these principled and expedient reasons for public involvement, we can add the implication of the points we have made earlier about our level of understanding of public responses: that for the foreseeable future there is going to be a need for a careful study and a well resourced consultation and education exercise specific to each proposed scheme.

\subsection{Developing public understanding}

There are many useful discussions, sets of guidelines, manuals for running specific mechanisms, and other resources for public participation initiatives, and it is not our purpose here to provide or review that sort of practical guidance $[4,16,17]$. We just make some observations that follow from our discussion.

First, public engagement needs

- to draw on attempts to understand the social bases of specific groups' responses to water recycling issues;

- to provide information materials and opportunities for developing understanding that address these concerns and requirements effectively, and in particular go well beyond just providing information in the form considered appropriate by technical experts;

- to provide opportunities for groups to develop an understanding of the issues which is not constrained by a discursive framework imposed by others; 
- $\quad$ and to aim at generating a reasoned and robust public evaluation of water recycling.

Second, we should treat the design, development and implementation of water recycling systems as a social learning exercise, and not necessarily in the terms envisaged by those providing information. The organisations involved in introducing schemes may have as much to learn as users and other outsiders.

It is likely, as Baumann argues from his review [3], and as Hurlimann and McKay found in their research at Mawson Lakes in South Australia, that 'a person's acceptance of the use of recycled water increases as their knowledge of the system develops' [18]. This is certainly a strong argument for a thorough education programme. It would be dangerous to assume, however, that dialogue will necessarily deliver a favourable outcome - that all individuals will become more supportive as they learn more, or that any one group will necessarily reach a favourable consensus as they get more information. There is evidence from studies of controversies that individuals - lay people and experts alike - may become further entrenched in their views, select only material that supports their position, and interpret ambiguity or uncertainty in a way that reinforces it. Moreover, where there are vocal opponents, group dynamics may be quite unpredictable.

\subsection{Consultation and control}

The implication of our reading of wider literatures on participation, public understanding of science and related areas, and our own work in other areas, is that the scope and terms of a consultation process, and its relation to the planning and management of a project, are as important as the content of information provided. When and how wider views are sought, the agenda of issues canvassed, how much control is offered, and the transparency of decision-making, all crucially affect people's willingness to participate and to accept the outcomes.

People are likely to expect a degree of control and involvement not only in the planning of the scheme but also in its operation. This points to the importance of measures to give users or their representatives

- continuing access to information about water quality and the performance of the scheme, not only in immediate technical and safety terms, but also on its contribution to water savings and environmental values - a measure which encourages not only acceptance but also the maintenance of good use practices and consumption patterns;

- continuing involvement in one-off or standing bodies to review the scheme;

- undertakings about accountability - making it clear what can or cannot be guaranteed, and what explanations will be given or sanctions will apply if agreed standards are not met or procedures not followed.

The scope of influence which potential users and other parties have in the development and operation of a scheme must be spelled out clearly in advance. Rather than being involved from the outset in discussions over different ways of achieving the wider aim of more sustainable water provision, those consulted have often been presented with a fully developed proposal for a recycling scheme. In such cases, the consultation process can at best affect the scheme in only limited ways:

- in the applications that are endorsed;

- in technical safeguards, management measures, the degree of user control and other aspects of practice at the point of use;

- $\quad$ in additional water quality monitoring requirements or safety criteria; 
- in some form of representation or accountability in the continuing management of the scheme.

In these circumstances participants may express dissatisfaction at the limits of their influence and the late stage at which they are being involved. They may justifiably question whether recycling is the most cost-effective means of demand reduction, and recognise that its role, scale and features might have been substantially different in the context of other water efficiency and environmental management measures.

Developers need to acknowledge that there may be more variables in the objectives, design and organisation of schemes, and in their management and regulation, than they have been prepared to acknowledge. They should allow users and the wider public a greater say in their selection, and indeed they may have to.

\subsection{Information needs in public consultation}

Our discussion so far indicates a nümber of crucial points about public education processes [19]:

- that people's understanding of recycling issues, and their views on them, develop during consultation as they tackle information and arguments - that is, any consultation process is inevitably an exercise in -information provision;

- that providers should try to address the concerns of the public in their own terms, rather than impose what is assumed to be a rational agenda and framework for discussion but which may marginalise other ways of framing the issues;

- that providers need to be careful not to impose specific value judgements in the guise of neutral information - for example, to assert that a particular level of contaminant is 'safe' without making clear what criteria they are using;

- that information needs will go well beyond technical details of the operation of the scheme and levels of contaminants.

Moreover audiences are likely to place great emphasis on impartiality and credibility of information, and to be suspicious of information provided by parties with a clear interest in a scheme.

Participants will need or request information on a variety of aspects:

- treatment and distribution processes;

- $\quad$ potential contaminants and associated health hazards;

- $\quad$ social and environmental costs and benefits;

- institutional structure and responsibilities;

- $\quad$ economics of the scheme and of water recycling in general;

- the regulatory regime for water quality and safety;

- experience of other schemes;

- comparisons with levels of risk in other systems and activities;

- $\quad$ results of studies of public responses and other consultation exercises;

- alternative means of achieving water management goals.

Beyond this, they may want to develop a better critical understanding to help them evaluate, question and process such information. They may raise questions about

- limitations, uncertainties and controversies in the assessment of health and environmental impacts; 
- different criteria for judging 'safety', and the assumptions involved, for example, in making risk comparisons or risk-benefit trade-offs;

- the way quantitative information is framed and presented;

- $\quad$ ethical and political issues in judging alternative courses of action;

- advantages and disadvantages of different organisational structures and regulatory instruments;

- different methods of valuing externalities;

- possible biases in information sources.

It is difficult to predict in what directions and to what depth participants will take their exploration of the issues. We should not underestimate, however, their ability and willingness to tackle complex information and develop searching and critical perspectives. Facilitators and advisers must be prepared to handle a variety of requests and to help develop participants' perspectives on a range of related issues.

\section{Qualitative research methods: discourse analysis in focus groups}

These challenges and requirements in understanding public responses and in providing effective public engagement form the background to our own research agenda.

\subsection{Focus groups and discourse analysis}

Clearly there is a need for a much more thorough qualitative exploration of people's responses to recycling and of their cognitive and cultural bases, among other aims so that quantitative work can be better designed and positioned more effectively in relation to the stages of a continuing educational process. First, there is much to be learned not only from general work on public participation but beyond that from studies of the public understanding of scientific and technical issues, and particularly of health hazards, in general terms and in the context of other sectors. Second, we see promise in research and consultation methods which draw on discourse analysis and acknowledge the importance of discourses - the language in which issues are framed and on which people draw in making arguments and developing understandings.

Language has significant material effects:

- it helps determine the outcome of debate and the shape of policies;

- it may restrict courses of action open to us;

- it favours particular outcomes, and may serve particular interests at the expense of others;

- it legitimates particular actions;

- and it tends to exclude other perspectives.

It also gives us a window into the assumptions, values and judgement processes of the people using it $[20,21]$.

We want to use focus groups for more than their traditional purposes of generating catalogues of concerns or preferences and gauging views on these. It is widely acknowledged that their loose structure and open-ended format allow participants to express themselves in terms of their choosing. Going beyond this, focus groups also allow us to probe and follow through; questions can be designed to explore and even provoke. Discourse analysis entails paying close attention to the language that people deploy, the way they argue, and the concepts and categories they draw on. Analysis of focus group discourse is expensive and time-consuming, and much to the chagrin of quantitative methodologists, does not provide anything of statistical value. It can however be rich and instructive. 
We plan to use focus group methods to develop an understanding of the heuristics people use for evaluating recycled water. From there we want to develop an information program for a specific recycling proposal. Participants will be provided with information about the scheme and we will use focus groups to explore their understanding of the treatment processes and their attitudes towards the use of recycled water from this particular scheme. The next stage is to devise material for a second series of focus groups which specifically addresses concerns or lack of understanding about the operation of the local system and the issues around it. The aim of the program is not to persuade participants that recycled water in general is beneficial or to accept the particular scheme, but to allow them to process information about the system and issues so that they can make informed decisions. This iterative process should allow participants to question and reconsider any views about recycled water they may have already formed.

Tailoring the information program and evaluation to a specific scheme and a specific audience is crucial: participants have an opportunity to voice concerns about actual technological processes and potential or actual local uses. We hope thereby to avoid the tendency of survey work to decontextualise responses [22], both in that they are not related to a particular stage in the development of people's understanding of the technology and the issues, and in that they may be isolated from specific proposals and circumstances. We hope the work will also shed light on some of the disparities we have referred to in survey results in the water recycling literature.

Discourse analysis also allows the context of discussion to be retained in reporting focus group dialogue. Reporting of focus group proceedings often aggregates discussion across groups and omits the context of participants' attitudes and preferences. Narrative analysis is one method we have found useful in retaining the context of focus group dialogue. In focus groups on other issues we have found that participants often relate stories of their situations and preferences, and that these stories provide a rich source for understanding cultural and community contexts. One story often prompts further stories from other participants, and that interplay is itself instructive. Narrative analysis should allow us to distil the essence of these stories while retaining the important aspects of the contexts in which they were told. It should also enable us to compare statements across contexts [23] - particularly between how people might describe their views on water reuse in an interview, and how they choose to engage in a particular consultation process.

McKerrow's preliminary work using focus groups along these lines [24] has already provided a number of interesting insights. It showed a distinction between willing acceptance and resignation - some people appear reluctant to broach issues they know they cannot influence - between a straight answer and an ironic defensive one, between a simple answer and a qualified or conditional one. These are all aspects that may be masked in responses to set questions. The work confirmed our expectation that trust and the degree of control over decision-making are crucial issues. It also indicated that people do not expect absolute purity - the notion common in discussions of risk perception and communication that people misguidedly expect 'zero risk'. Instead participants seemed comfortable with the idea of a spectrum of water quality, rather than putting recycled water in a qualitatively different category.

\section{Accommodating conflicting discourses in policy analysis and planning}

The second aspect of our empirical work will examine the usefulness of discourse-based approaches for public involvement. Programs which genuinely seek to 
incorporate public preferences into decision-making processes need methods of policy analysis and planning which can accommodate varied public discourses. The field of participatory policy analysis and planning provides a rich source of methods for developing such a practice. Participatory policy analysis is a deliberative process in which a diversity of participants are assisted to consider policy or planning options and articulate a position on them [25]. The policy analyst or planner identifies affected sectors of a community, provides education on the issues, and distils the essence of their discourse in a balanced manner.

Narrative policy analysis $[26,27]$ provides a method of analysing public discourse and reconciling diverse and potentially polarised positions on policy and planning issues. It initially entails the identification of dominant narratives, and the way they express uncertainty and complexity, and non-stories and counter-stories which are contrary to that dominant narrative [27]. As these narratives are expressed and analysed, a meta-narrative may evolve from their interplay. In polarised controversies, formulating a meta-narrative provides a framework for viewing and reconciling opposing viewpoints without losing their diversity or slighting any one. To allow a meta-narrative to emerge it is vital that diverse and perhaps marginalised viewpoints are heard and that protagonists are provided with equal access to resources, such as detailed information on the issue:

The method is consistent with the tenets of public involvement we have referred to. For us as analysts; it allows the discourses of technical experts, politicians, policy analysts, planners, and diverse communities to be viewed together from the outset. Beyond that, though, the development of a meta-narrative may present a way forward in a stalled planning process and allow all those viewpoints to be considered in a final decision.

We want to extend this method of narrative policy analysis to public participation programs for water recycling. In work on other water planning issues, we have found that allowing the plurality of voices of community groups, experts and officials to be heard together, so that there is an interplay of discourses, does indeed sometimes produce a meta-narrative [28]. It represents a conciliatory framework, one that has been developed by a variety of participants in interaction, rather than created post hoc by an analyst. In the second stage of our process, where we provide information tailored to the needs and requests of participants, we will introduce technical practitioners and water utility representatives to them so that they can interact on the range of technological, health, end use and other issues, rather than just providing them with the packaged information those groups have decided is appropriate. We hope this will lead to an interplay of different discourses that we can analyse using narrative policy analysis.

It is important to provide for involvement throughout the policy and planning process, including the final decision on a scheme - the point at which other groups are typically excluded again, even when their views have been sought earlier and even when a crisis in the process has forced that consultation. Beyond that, the same justification applies to involvement in the implementation and continuing monitoring of the scheme. We anticipate that a discourse-based approach will be useful at all of these stages in a participatory process.

\section{Conclusion}

This paper has sketched what we see as the key shortcomings of our current understanding of public responses to water recycling and of current provision for public involvement in its planning and implementation. From our interpretation of existing work in the sector, and of wider literatures on public understanding and participation, 
we have offered an outline and a justification of our own research agenda exploring discourse analytic methods. We look forward to returning with a substantive contribution both to understanding people's views on reuse and to methods for fostering a deeper and more durable public evaluation of the options.

\section{Acknowledgement}

This work is proudly supported by the International Science Linkages programme established under the Australian Government's innovation statement Backing Australia's Ability: It is funded by the Commonwealth Department of Education Science and Training for the project $O z-A Q U A R E C$ : Integrated Concepts for Reuse of Upgraded Wastewater in Australia (CG030025). It forms part of the EU 5th Framework Project AQUAREC: Integrated Concepts for Reuse of Upgraded Wastewater. We thank Colleen Lux and an anonymous reviewer for their useful comments on our draft.

\section{References}

[1] P. Dillon, Reuse on the rise, Waste Management and Environment 11(10), 2000, pp. 27-30.

[2] WateReuse Foundation, Request for Proposals: Marketing Strategies for NonPotable Recycled Water, WRF-03-005, Jun 2003.

[3] D.D. Baumann, Social acceptance of water reuse, Applied Geography 3, 1983, pp. 79-84.

[4] T.W. Hartley, Water Reuse: Understanding Public Perception and Participation, Water Environment Research Foundation, Alexandria VA, 2003.

[5] M. Po, J. Kaercher \& B.E. Nancarrow, Literature Review of Factors Influencing Public Perceptions of Water Reuse, CSIRO Land \& Water, Apr 2004.

[6] W.H. Bruvold, Public Attitudes Towards Wastewater Reclamation and Reuse Options, University of California, 1979.

[7] W.H. Bruvold, Public opinion on water reuse options, Water Pollution Control Federation 60, 1988, pp. 45-49.

[8] D.R. Rowe and I.M. Abdel-Magid, Handbook of Wastewater Reclamation and Reuse, CRC Press, Boca Raton FL, 1995, pp. 293-295.

[9] B. Wynne, Risk and social learning: reification to engagement, in S. Krimsky and D Golding, (Eds.), Theories of Risk, Praeger, New York, 1992.

[10] B. Wynne, Redefining the issues of risk and public acceptance: the social viability of technology, Futures 15, 1983, pp. 13-32.

[11] J. Marks, Advancing community acceptance of reclaimed water, Water 31(5), 2004, pp. 46-51.

[12] A. Hurlimann and J. McKay, Attitudes to reclaimed water for domestic use: part 2 - trust, Water 31(5), 2004, pp. 40-45.

[13] S.R. Arnstein, A Ladder of Citizen Participation, Journal of the American Institute of Planners 35 (1969), pp. 216-224.

[14] M. Pollak, Public Participation, in H. Otway and M Peltu, (Eds.), Regulating Industrial Risks: Science, Hazards, and Public Protection, Butterworths, London, 1985 , pp. 76-93.

[15] S. Russell, Community Responses and Consultation, notes for short course Water Recycling 2005, University of Wollongong, 9-11 Feb 2005.

[16] R. Harding, Environmental Decision-Making, Federation Press, Sydney, 1998, ch.6. 
[17] W. Sarkissian et al., Community Participation in Practice: the Community Participation Handbook, ISTP Murdoch University, Murdoch WA, 1986, and other handbooks in a series.

[18] A. Hurlimann and J. McKay, Community attitudes to an innovative dual Water supply system at Mawson Lakes South Australia, paper to OzWater 2003, Perth WA, 2003.

[19] AQUAREC, Participatory Planning for Water Reuse Projects: a Handbook of Principles, Tools and Guidance (forthcoming)

[20] S. Russell, Beyond unplumbing the blockages: a wider role for social analysis in water reuse, paper to workshop Participative Planning for Municipal Wastewater Reclamation \& Reuse Projects at the IWA 4th World Water Congress, Marrakech, 19-24 Sep 2004, also in Water Intelligence Online, Oct 2004 $<$ http://www.iwaponline.com/wio/2004/10/wio200410001.htms

[21] C. Waterton and B. Wynne, Can focus groups access commünity views? in R. Barbour and J Kitzinger, (Eds.), Developing Focus Group Research: Politics, Theory and Practice, Sage, London, 1999, pp. 127-143.

[22] J. Potter and M. Wetherell, Discourse and Social Psychology: Beyond Attitudes and Behaviour, Sage, London, 1987.

[23] G.R.Hampton, Enhancing public participation through narrative analysis, Policy Sciences (in press).

[24] M. McKerrow, Public Perceptions of Wastewater Recycling: an Argument for Effective Public Participation, Engineering Honours dissertation, University of Wollongong, Nov 2003.

[25] P. Deleon, Reinventing the policy sciences: 3 steps back to the future, Policy Sciences 27, 1994, pp. 77-95.

[26] T.J. Kaplan, Narrative structure of policy analysis, Journal of Policy Analysis and Management 5, 1986, pp. 761-788.

[27] E.M. Roe, Narrative Policy Analysis: Theory and Practice, Duke University Press, Durham NC, 1994.

[28] G.R. Hampton, Public involvement in decision making, unpublished manuscript 2005. 